\title{
The interactive role of job stress and organizational perceived support on psychological capital and job deviation behavior of hospital's nurses and staffs
}

Abolfazl Ghasemzadeh ${ }^{1}$, Shiva Maleki ${ }^{2}$, Masoud Khadem Hosini ${ }^{3}$

\author{
Journal of Research \& Health \\ Social Development \& Health Promotion \\ Research Center \\ Vol. 7, No. 1, Jan \& Feb 2017 \\ Pages: $572-580$ \\ DOI: 10.18869/acadpub.jrh.7.1.572 \\ Original Article
}

1. Department of Education, Faculty of Education and Psychology, Azarbaijan Shahid Madani University, Tabriz, Iran

2. Correspondence to: Department of Education, Faculty of Literature and Humanities,Lecturer of Payam-e-Noor University of Ardabil, Ardabil, Iran

Email: shiva.maleki.89@gmail.com

3. Department of Education, Faculty of Literature and Humanities, Urmia University, Urmia, Iran

Received: 3 Sep 2014

Accepted: 12 Jan 2015

How to cite this article: Ghasemzadeh A, Maleki Sh, Khadem Hosini M. The interactive role of job stress and organizational perceived support on psychological capital and job deviation behavior of hospital's nurses and staffs. J Research Health2017; 7(1): 572580 .

\begin{abstract}
The phenomenon of job stress is an inevitable part of professional lifeandintheactivitiesandefficiency is reflected in theorganization. This study aimed to identify and predict the relationship between psychological capital and job deviation behavior through job stress regarding the moderating role of perceived organizational support. This study is correlation by using descriptive methods for applied goals. Standard questionnaire was used to collect data. 180 participants was estimated and stratified random sampling. The results showed the significance of the relationship between the variables except the relationship between deviant behaviors with psychological capital. Also, the interactive role of job stress and perceived organizational support on psychological capital and job deviation behavior was confirmed. This means that for the hospital's nurses and staffs with job stress, increasing perceived organizational support associated with enhancing psychological capital and decreasing job deviation behavior. These results emphasize necessity of recognizing interactive role of job stress and perceived organizational support in psychological capital and job deviation behavior.
\end{abstract}

Keywords: Job, Organizational, Support

\section{Introduction}

In recent decades, the considerable progress in technology and industry has brought wave of stress that would be reduced public health. Stress has negative effects on human activities in different psychological, physical, and family fields [1]. Each job is associated with stress but some jobs are more stressful for the sensitivity of their responsibilities [1]. Nurses are one of the groups that suffer the highest stress [2]. Symptoms of stress include; professional dissatisfaction, error increase, and decrease of general health [1]. When stress occurs, it causes that person doesn't enjoy work activities [3]. In the research literature on stress and stress is determined that stress is correlated with physical and mental illnesses [4]. Based on [5], it requires that staffs can cope with stressful events and 
conditions in the workplace so minimize stress symptoms. Based on [6], psychological capital is one factor that increases one's attempt for changing stressful situations, making one prepared for action guaranty their goals, relying on positivist psychological elements. So far, three important capital, financial capital, human and social organization has been of interest to researchers. But, [6]. Introduced another form of capital as psychological capital and claim that this capital goes beyond social and human capital and are considered as competitive advantage for the [6]. Psychological capital is new issue that in the past decade has been applied in the field of organization and management and has attracted the attention of experts [7]. Although over the years substantial scientific justification is dedicated to reducing stress, but stress in the workplace has become growing concern for managers of human resources and it's time that perspectives and new research would be occurred [5]. Scholars of organizational behaviors in organizations and work environment are trying to examine content, antecedents, and consequences of stress at work and still ongoing investigation data obtained from a large sample of working adults in a variety of industries, shows that psychological capital may be the key of the signs of stress [5]. Findings of psychological capital indicated there is significant relationship between it and organizational consequences, for example, psychological capital affected the stress levels of employees [8]. In this respect, [5] a study entitled "psychological capital: a positive source of personnel's stress fighting" conducted and offered practical strategies for developing psychological capital of the staffs to help them deal with stress at work. Also [9]. examined stress resources and mental health of Chinese nurses, concluding that stress intensity which nurses experienced at work is positively correlated with mental health. Then, [10] showed that stress from much work is correlated with stress and psychological disorders. Symptoms like absenteeism, indifference at work, and reducing motivation is higher in these people.

There are studies about relationship between psychological capital and other factors [7,11-13]. But in general, because of novelty of psychological capital theory, there are few domestic studies on psychological capital. Work environment is the area for showing behaviors which have important consequences for the people, organizations, and society. Some of these behaviors are improper or diversionary [14] referred to by the names like diversionary behaviors at work and antisocial behaviors [14]. In conceptual terms, diversion behaviors are those by which people violate the rules, traditions, and formal policies of the organization in different fields, providing the grounds for hurting people and the organization [15]. These behaviors at work are deliberate in contrast with organizational norms, hurting organizational functions [16].

Professional demands which are stressors at work have many consequences that one of them is increasing diversion behaviors [17]. Based on research evidences, stress and job burnout are antecedents of diversion behaviors. When the pressure level in the work environment and the exhaustion of people rises because of the negative experienced emotions and tendency to return to the conditions of before pressure, people commit diversion behaviors to retaliate injustices [15]. Diversion behaviors have a retaliating nature based on theoretical evidences [16]. Stress, burnout, and weakness of energy and vivacity are mechanism that activates this retaliation sense. When people feel that exhaustion overcomes them, they show recursive behaviors for returning energy. In such conditions, tendency to diversion behaviors increases [17].

Researches was conducted separately about the correlation of diversion behaviors at work and different variables [14-17] Recent years much attention to factors moderating the relationship between life events and mental disorders and physical focus and 
creates a new approach to the study of stress and its prevention methods [4]. Perceived organizational support is one of those mediating variables. Now that two decades pass from starting the studies on perceived organizational support, its importance is growing more than before and such studies develop faster [18]. The idea of perceived organizational support was introduced by [19] in the organizational literature. Then, the scholars attended the ways of forming perceived organizational support, examining the effects and consequences of organizational support in personal and organizational fields [20]. This support is general belief that the employees of an agencywide overall value for the role, contribution and believes in taking care of their well-being. Thus, perceived organizational support shows staff perception about their commitment in the organization [21]. It refers to staff perception which how much organization respects the staff's cooperation with the organization and their well-being in it $[18,19]$.The staffs feel interest and belief in an organization based on the value the organization offers to them or their well-being. This belief is perceived organizational support [22]. Theory of organizational support suggests that the staffs form beliefs around the degree of support the organization offers to their interests and values shaped based on the interaction with organizational agents like supervisors and managers [23]. Supportive behaviors of leaders and organizational atmosphere can produce perceived organizational support [19].

A trend of researches offers evidences connecting perceived organizational support with work results of the staffs [24]. Although numerous studieshave addressed relationship between perceived organizational support with personal, professional, and organizational variables [21], and probed its dimensions and their correlations with other variables $[18,22$, 23,25 ] but these issues were introduced about 20 years ago and its importance in the discussions about work, industrial and organizational psychology, and managing organizational behaviors has been broadly accepted and studied outside the country, there are few studies in this regard by the researchers in Iran [25].

As well as the role of the moderating variable, however, perceived organizational support is a moderator variable was considered by researchers and research performance as a factor that could mediate the relationship between independent and dependent variables have shown. For example, [26] found that perceived organizational support affects the correlation of actions of human resources, emotional commitment, and dropout intention. Also [27] found that perceived organizational support is the mediator of the positive correlation between organizational bonus, procedural justice, and the supervisor's support with commitment. Then [28] reported that perceived organizational support is the mediator of the correlation between such support and intrarole duties no study was found in this regard in Iran, so further studies are required here. As mentioned before, no study was found to have a direct reference to the interactive effect of job stress and perceived organizational support on psychological capital and diversion behavior. Thus, such studies seem necessary in Iran since hospital's staffs are important components of hygiene and medical care system and their deficiency will have unrepeatable damages [12]. Accordingly, this study aims to identify and predict the relationship between psychological capital and job deviation behavior through job stress regarding moderating role of perceived organizational support.

The conceptual pattern of the study regarding the correlation of job stress, psychological capital's consequences, and diversion work behaviors with mediating role of perceived organizational support is shown in Figure 1. Based on this model, the main question was whether perceived organizational support moderated relationship between job stress and psychological capital and deviant behavior? 


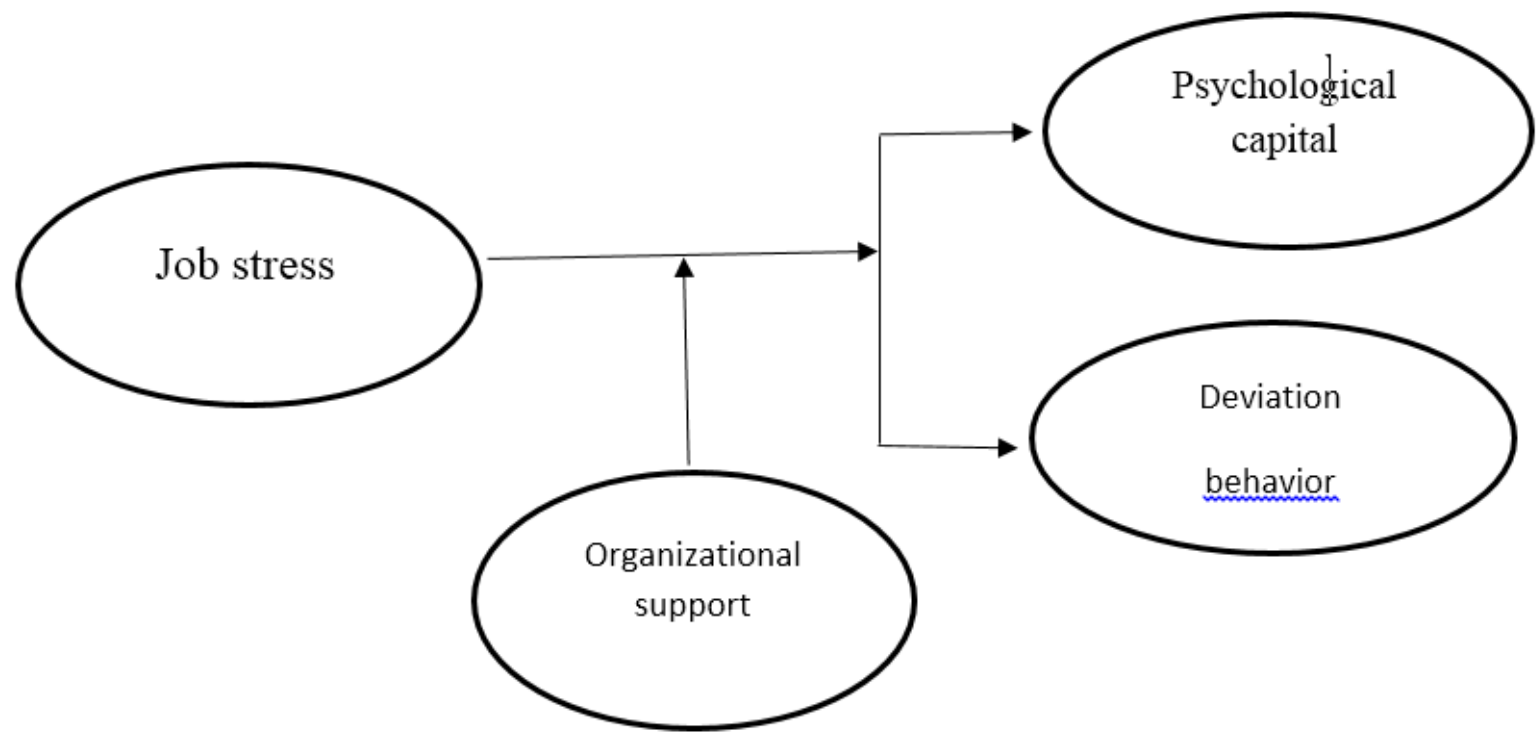

Figure 1 Conceptual pattern of the study

\section{Method}

This study is correlation using descriptive methods for applied goals. Statistical population included all 320 nurses and staffs of Alinasab Hospital in Tabriz in 2014. Sample size of 180 people was estimated by using Morgan Table and stratified random sampling. From returned questionnaires, 320 of them were applicable in this study. To collect data, standard questionnaires were used.

Four standard questionnaires were used to collect data:

Perceivedorganizational support's questionnaire: This questionnaire was officially introduced by [19] in the literature of organizational theories and was recognized proper for measuring civilized organizational behavior. It used 5-point Likert scale (1. quite disagree, 5. quite agree). It was translated by [21] whose consistency and reliability were calculated and identified by industrial and organizational researches.

Job stress questionnaire: Job stress was measured by using a 6 items tool which has been prepared by the? House and Rizzo. It had 5-point Likert scale (1.quite disagree, 5. quite agree) [29] Validity and reliability of this tool has been confirmed in previous research [30].

Psychological capital's questionnaire: It included 24 questions and 4 subscale of hopefulness, endurance, optimism, and selfefficiency in which each subscale had 6 elements with 6-point Likert scale (Strongly disagree to strongly agree). Questions 1-6 related to self-efficiency subscale, questions 7-12 were about hopefulness, questions 1318 were about endurance, and questions 1924 were related to optimism. To obtain the mental capital, the score of each subscale was obtained separately and then all of them were considered as the total score of psychological capital. Consistency and validity of this tool were confirmed by previous studies [11]. In this study the Cronbach's alpha coefficient was used to evaluate the reliability of the questionnaire. The internal consistency for the total scale was 0.80 .

Job deviation questionnaire: Mixture of 15 questions of [31] and [32] was used to measure job deviation. It was translated by [33] whose consistency and reliability were calculated. [33] Reported Cronbach's Alpha of 0.86. It used a 6-point scale (1. Never, 6. Always).

Cronbach's Alpha was used to estimate consistency coefficients of the elements of the questionnaire whose reliability coefficients were higher than 0.70. (0.86 for perceived organizational support, 0.70 for job stress, 0.81 for psychological health, 0.70 for job deviation behavior). Thus, all questionnaires had high consistency. As well as to the validity of the questionnaire, despite repeated standard 
tools and use them in research, management and psychology, data were factor analysis of this scale in the sample. This exploratory analysis using principal component analysis method (PC) with varimax rotation was conducted. Value of KaiserMayer-Olkin (sampling adequacy ratio) equal to 0.70 and the square was 2756.8 Bartlett's test of sphere city was significant at 0.01 level and adequacy of signs and instance variables for factor analysis. The results are confirmed and the cumulative variance is obtained about 0.74 . In this study, data analysis techniques, descriptive statistics (mean and standard deviation) and inferential statistics, Pearson correlation coefficient and moderator multiple regression were used by SPSS- 19 .

\section{Results}

In this study $64 \%$ of the participants was female and $36 \%$ was male. $75 \%$ of the staffs had experiences less than 10 years. Most staffs $(50 \%)$ had Bachelor of Arts/Science degree. Table 1 shows the mean and standard deviation of nurses and staffs' scores for the variables of job stress, organizational support, psychological health, and job deviation behavior. Staffs' responses show the feeling of higher than mean in organizational support ( 0.81 above mean). The data showed feeling of higher than mean in staffs towards job stress, psychological health, and job deviation behavior.

Table 1 Descriptive statistics of research variables

\begin{tabular}{lcccc}
\hline & Job stress & Organizational support & Psychological capital & Job deviation behavior \\
\hline Mean & 3.29 & 3.14 & 3.90 & 1.4 \\
SD & 0.85 & 0.89 & 0.47 & 0.87 \\
\hline
\end{tabular}

Correlation of research variables are shown in Table 2 It shows that correlation coefficient of research variables are significant.

Table 3 shows the results of modifying regression test. Results show that support $(\mathrm{p}<0.05$ and $\beta=0.18)$ and job stress $(p<0.05$ and $\beta=-0.51)$ predict psychological health. In the second step, the interaction ofstress and organizational support entered the equation which was significant and predicting mental health.

\begin{tabular}{lcccc}
\multicolumn{5}{l}{ Table 2 Correlation of research variables } \\
\hline Variable & Stress & Support & Psychological capital & Behavior \\
\hline Job stress & 1 & & & \\
Organizational support & $* *-0.66$ & 1 & & \\
Psychological health & $* *-0.57$ & $* * 0.46$ & 1 & 1 \\
Job deviation behavior & $* 0.12$ & $* *-0.27$ & 0.09 & \\
$* \mathrm{p}<0.05,{ }^{* *} \mathrm{p}<0.01$ & & & &
\end{tabular}

Table 3 Results of modifying regression test for predicting psychological capital

\begin{tabular}{lccc}
\hline & $\beta$ & $\Delta \mathrm{R}^{2}$ & sig. \\
\hline $\begin{array}{l}\text { First step: main effects } \\
\begin{array}{l}\text { Organizational support } \\
\text { (O) }\end{array}\end{array}$ & $* * 0.18$ & 0.21 & 0.000 \\
$\begin{array}{l}\text { Stress (S) } \\
\text { Second step: interaction }\end{array}$ & $* *_{-} 0.51$ & 0.33 & 0.000 \\
of $\mathrm{O} \times \mathrm{S}$ & $*_{-} 0.19$ & 0.37 & 0.003 \\
\hline $180=\mathrm{n}$ and ${ }^{* *} \mathrm{p}<0.01,{ }^{*} \mathrm{p}<0.05$ & & &
\end{tabular}

It was observed that determination coefficient of stress and perceived organizational support can identify $37 \%$ of the variance of psychological health. B coefficient of perceived organizational support is positive for predicting psychological health of the staff. B coefficient of stress is -0.51 . But, the interaction of stress and organizational support reduces negative effect of stress from -0.51 to -0.19 . Thus, perceived organizational support plays a mediating 
role in the relationship between job stress and psychological health.

Table 4 Results of modifying regression analysis for predicting job deviation behavior

\begin{tabular}{|c|c|c|c|}
\hline & $\beta$ & $\Delta \mathrm{R}^{2}$ & sig. \\
\hline \multicolumn{4}{|l|}{$\begin{array}{l}\text { First step: Main } \\
\text { effects }\end{array}$} \\
\hline $\begin{array}{l}\text { Organizational } \\
\text { support }(\mathrm{O})\end{array}$ & $* *-0.56$ & 0.07 & 0.000 \\
\hline Stress (S) & $* * 0.51$ & 0.20 & 0.000 \\
\hline $\begin{array}{l}\text { Second step: } \\
\text { interaction of } \mathrm{O} \times \mathrm{S}\end{array}$ & $* 0.14$ & 0.22 & 0.049 \\
\hline
\end{tabular}

Table 4 shows the results of moderator regression test. Organizational support $(\mathrm{p}<0.05$ and $\beta=-0.56)$ and job stress $(\mathrm{p}<0.05$ and $\beta=$ -0.51 ) predict job deviation behavior. In the second step, the interaction of stress and organizational support entered the equation which was significant. It was observed that determination coefficient of stress and perceived organizational support can identify $22 \%$ of the variance of job deviation behavior.

$\mathrm{B}$ coefficient of perceived organizational support is negative for predicting job deviation behavior of the staffs. B coefficient of stress is 0.51. But, the interaction of stress and organizational support reduces positive effect of stress on job deviation behavior from 0.51 to 0.14 . Thus, perceived organizational support plays a mediating role in the relationship between job stress and job deviation behavior.

\section{Discussion}

This study aimed to identify and predict the relationship between psychological capital and job deviation behavior through job stress regarding the moderating role of perceived organizational support. Results showed that perceived organizational support plays mediating role in the correlation of job stress and psychological capital. This finding is consistent with research that directly was not found, so congruent and incongruent with the results of the research are avoided.

To justify this relationship can be a significant contribution in the context of creating organizational support to reduce the negative impact of job stress and it's about results. Capability and psychological capacity of the people can directly reduce stress in a way that some studies have shown the correlation of these variables and [5] showed that psychological capital is the factor that helps the better understanding of stress symptoms. Knowing that the stress from different factors at work may lead to physical, mental, performance, and emotional problems [4], and by forcing of people to spend their physical and mental energy, vitality and energy of people to undermine, the lower levels of vitality and energy in a forward chain, provide grounds for undermining the positive behavioral tendencies [17]. So even if someone have the talent and capacity to do a job, without feeling the support of the organization may not necessarily be able to overcome all stress in their work environment and failed to demonstrate a level of performance. Based on [13], psychological capital can't work in vacuum. Thus, supportive organizational atmosphere can be useful and encourage the staff to show positive work behaviors. For example, when a failure occurs due to staff's error, those who are supportive atmosphere likely will experience higher levels of flexibility so that instead of stress and fear of punishment due to their mistake, they can focus on their work, failing to back overcome and effectively respond in a positive way and the same resilience (psychological capital component) that based on [6], in facing to difficulties and hardships, tolerance and return to the first place to achieve success with it. Thus, supportive systems at work can modify the effects of stressful events, leading to the experience of positive feelings as one 
element of psychological capital. Researchers have stressed mediating role of social support in stress [34]. Authors found that supports from supervisors, coworkers, and friends can reduce anxiety and depression [35]. also Researchers [3] showed that people with higher support at work experience lower stress, act better, and feel more satisfaction and [36] found that reducing stress and increasing support from nurses can improve their psychological health. Resultsconfirmed themediatingroleofperceived organizational support in the correlation of job stress and job deviation behavior. Although no literature was found in this regard, this finding has rational justifications. Pressure at different areas especially injustice predicts job deviation behaviors. Researchers have shown that trust has a significant effect on job deviation behaviors [14]. And[37] suggested trust as an essential element of the terms associated with the perceived support and the outcome of their work. When people are stressed, they spend much psychological and physical energy to remove it [38]. The energy levels followed by positive emotional state can be reduced, thus more ready to tend to deviant behaviors as a form of compensatory behavior to find and return the previous status [17]. Based on the fact that the shortage of supportive resources along with other work factors are considered as the stressors at work [2], the more support they feel at work, the more their stress decreases at work then [39] suggested that the basis of job stress theory is that one stressor is personal factors, formed based on the feelings, experiences, and perceptions about their own and others' behaviors. Thus, when the staffs have perceptions about organizational trust and support, they feel that they have fair chances at work, reducing their stress [40] also [14] showed that trust has a significant effect on job deviation behaviors and trust level of the people towards their supervisors and organizations significantly affects job deviation behaviors and finally [7] showed that reducing trust level leads to occurrence of job deviation behaviors. While, close relations of the staff with their supervisors increases positive return and decreases job deviation behaviors.

There were limitations for this study. Statistical population was limited to the nurses and staffs of Alinasab Hospital in Tabriz. So, generalizing its results to other studies should be with caution. Further studies can be conducted in bigger samples and their results should be compared with this one. Also, using self-reported questionnaire as the only measurement tool in this study can be limitation.

\section{Conclusion}

For the sensitivity of the tasks of nursing, stress is inevitable part of their life. Thus, managers should find ways for reducing their stress by material and spiritual organizational support. Although stress can't be prevented fully, inviting consultants and experts for improving work conditions and stress management can be the best possible solution at workplace.

\section{Acknowledgements}

We fully appreciate all the nurses and the employees of Alinasab hospital of Tabriz who helped us in conducting this research.

\section{Contribution}

Study design: GHA

Data collection and analysis: KHHM, GHA

Manuscript preparation: MSH

\section{Conflict of Interest}

"The authors declare that they have no competing interests."

\section{Funding}

The author (s) received no financial support for the research, authorship and/or publication of this article.

\section{References}

1- Mohamadi SH. Comparing confrontation mechanisms, job burnout, and mental health among teachers of Iran and India. Journal of Educational Innovations 2007; 16: 60-96.

2- Noorian K, Parvin N, Mehrabi T. The relationship between stressful job factor and general health of nursing staff in hospital of medical university of 
Isfahan. Journal of Midwifery and Nursing Faculty of Rafsanjan2010; 1,2: 45-52.

3- Asgari P, Nakalzadeh M. The relationship between job stress, social support, and job stress in the staff of national excavation company. Journal of New Finding in Psychology2011; 35-50.

4- Hasanshahi M, Daraei M. The effect of strategies for confronting with stress on mental health of students: Mediating effect of psychological difficulty. Journal of Knowledge and Research in Psychology2005; 26: 77-98. 5- Avey JM, Luthans F, Jensen SM. Psychological capital: a positive resource for combating employee stress and turnover. Hum Resour Management2009; 5: 677-93.

6- Luthans F, Avolio BJ, Avey JB, Norman SM. Positive psychological capital: Measurement and relationship with performance and satisfaction. Personnel Psychology2007; 60(3): 541-72.

7- Hozoori M, Salehi A, Danaei H, Najari R. Designing promotion model of psychological capital in public organizations of Iran: identifying the role of management functions of human resources. Journal of Management Studies in Iran2013; 3: 1-27.

8- Avey JB, Luthans F, Ronda SM, Palmer NF. Impact of positive psychological capital on employee well-being over time. J Occup Health Psychol2010; 15(1).

9- Wong D, Leung SS, Lam D. Mental health of Chinese nurses in Hong Kong: the roles of nursing stresses and coping strategies. On Line Journal of Issues in Nursing2001; 5; [4 screens]. Available atURLhttp: //www.nursingworld.org/MainMenuCategories/ A N A Marketplace/ANAPeriodicals/OJIN/ TableofContents/Volume62001/No2May01/Article Previous Topic/Mental Health of Chinese Nurses in Hong Kong.html

10- Margolis BL. Job stress: on unlisted occupational hazard. J Occup Med1974; 16(10): 659-61.

11- Bahadori Khosroshahi J, Hashemi T, Birami M. The relation between psychological capital and personal qualities and job satisfaction in bookkeepers of public libraries of Tabriz. Bimonthly of Researcher2012; 6: 312-8.

12- Nisi A, Arshadi N, Rahimi E. The casual relationship between psychological capital, positive emotions, psychological well-being, job performance, and job requirement. J Organ Behav2011; 1: 19-46.

13- Luthans F, Norman SM, Avolio BJ, Avey JB. The mediating role of psychological capital in the supportive organizational climate-employee performance relationship. J Organ Behav2008; 29: 219-38.

14- Arshadi N, Priayi S. Credibility of employee, employer, and interpersonal trust as an introduction for distracted behaviors of work environment. Journal of Vocational and Organizational Consultation2012; 13:
83-100.

15- Berry CM, Ones DS, Sackett PR. Interpersonal deviance: organizationnal deviance, and their common correlates: a review and Meta-analysis. $J$ Appl Psychol2007; 92: 410-24.

16- Bennett RJ, Robinson SL. Development of a measure of workplace deviance. J Appl Psychol2000; 85(3): 349-60.

17- Golparvar M, Vaseghi Z. The relationship between autocratic management, perceived emotional pressure, organizational injustice, diversionary, and civilizedorganizational behaviors. Journal of Industrial Management 2011; 6: 119-30.

18- Taleghani GH, Divandari A, Shirmohamadi M. The effect of perceived support from organization on staff commitment and organizational performance: a study in branches of Mellat Bank in Tehran. Journal of Management Sciences of Iran2009; 4(16): 1- 25.

19- Eisenberger R, Huntington R, Hutchison S, Sowa D. Perceived organizationalsupport. Journal of Applied Psychology1986; 71(3): 500-7.

20- Zaki MA. Investigating and measuring organizational support. Journal of Administration and Economics of Esfahan University2006; 18(3): 103- 23. 21- Arizi H, Golparvar M. Path pattern of perceived organizational support relation with professional and organizational variables. Journal of Management Researches in Iran2010; 15(4): 147-73.

22- Doaei H, Mortazavi S, Noori A. Modeling the effect of understanding organizational support on OCB: case study of 5-star pars hotel. Research Paper of Executive Management2010; 10(1): 13- 32.

23- Rhoades L, Eisenberger R. Perceived organizational support: a review of theliterature. $J$ Appl Psychol2002;87(4): 698-714.

24- Chen Z, Aryee S, Lee C. Test of a mediation model of perceived organizational support. $J$ Vocat Behav2005; 66: 457-470.

25- Shakerinia I, Nabavi S. The relationship between job satisfaction, and perceived organizational support with staff organizational commitment in police department of Gilan. Journal of Police Management Studies2010; 5(4).

26- Wayne SJ, Shore LM, Liden RC. Perceived organizational support and leader-member exchange: a social exchange perspective. Acad Manage J1997; 40: 82-111.

27- Rhoades L, Eisenberger R, Armeli S. Affective commitment to the organization: thecontribution of perceived organizational support. J Appl Psychol2001; 86: 825-36.

28- Moorman RH, Blakely GL, NiehoVB. Does perceived organizational support mediate the relationship between procedural justice and 
organizational citizenship behavior? Acad Manage J1998; 41: 351-7.

29- Breaux DM, Munyon TP, Hochwarter WA, Ferris GR. Politics as moderator of the accountability job satisfaction relationship: evidence across three studies. Journal of Management2009; 35: 370-26

30- Ghasemzade A, Hasani M, Zavar T. Fitness of casual-structural relations of personal features with stress and OCB regarding mediating effects of personal responsiveness behavior. Journal of Research in Social Psychology 2013; 3(9): 79-94.

31- Mulki JP, Jaramillo F, Locander WB. Emotional exhaustion and organizational deviance: can the right job and a leaders' style make a difference? J Bus Res2006; 59: $1222-30$.

32- Robinson SL, Bennett RJ. A typology of deviant workplace behaviors: a multidimensional scaling study. Acad Manage J1995; 38(2): 555-72.

33- Golparvar M, Nayeri SH, Mahdad A. Stress, emotional exhaustionand organizational deviant behaviors in the Steel company. Evidence forstress model-burnout-instability-compensation. Journal of New Findings Inpsychology2010; 2(8): 19-34.

34- Fleming MZ, Mc Gowan BR, Robinson L, Spitz J, Salt P. The body image of the postoperative female- to male transsexual. J Consult Clin Psychol1982; 50(3): 461-2.

35- Moradi A, Taheri S, Javanbakht F, Taheri A. Metaanalysis of research onthe relationship between mental health and social support in Iran. Journal of Behavioral Sciences 2012; 6: 565-73.

36- Chang EM. The relationships among work place stressors, coping methods, demographic characteristics and health in Australian nurses. J Prof Nurse 2006; 22(1): 30-8. 37- Eisenberger R, Cotterell N, Marvel J. Reciprocation ideology. J Pers Soc Psychol1987; 53: 743-50.

38- Ouyang Y. The mediating effects of job stress and job involvement under job instability: banking service personnel of Taiwan as an example. Journal of Money, Investment and Banking2009; 11(1): 16-26.

39- Soleimani N, Abaszade N, Niaz Azari B. The relationship between work ethics, job satisfaction, and job stress of the staff in technical training department of Tehran. Journal of Quarterly of New Approach in Educational Management2012; 3(1).

40- Mohamadzade H, Kozazi H, Javaheri A. The effect of job satisfaction and organizational commitment on dropout of the staff. Bimonthly of Human Development of Police 2008; 5: 41-57. 